\begin{tabular}{||lcc||}
\hline \multicolumn{2}{|l|}{ Egyptian Journal of Social Work (EJSW) } & http://ejsw.journals.ekb.eg \\
Print ISSN: 2356-9204 & Online ISSN: 2356-9212 & Vol 8, Issue 1, June 2019 \\
\hline \hline
\end{tabular}

\title{
Post-traumatic stress among elderly Syrian refugees
}

\section{Hanaa Faize Mubarak (PhD)}

Associate Professor-Social Casework Department Higher Institution of Social Work- Alexandria 


\section{Hanaa Faize Mubarak (PhD)}

\section{Post-traumatic stress among elderly Syrian refugees}

Associate Professor-Social Casework Department

Higher Institution of Social Work- Alexandria

\section{Abstract:}

The experience of being a refugee, compounded with aging and mental health issues, constitute an exceptional situation for individuals. This study attempts to assess post-traumatic stress among elderly Syrian refugees living in Egypt. Harvard Trauma Questionnaire Part IV was administered on (47) elderly Syrian refugees ( $>60$ years old) who are living in Egypt due to the recent conflicts in Syria.

The results suggest that all subjects suffer from chronic posttraumatic stress disorder (PTSD), ranging from average in $(89.4 \%)$ and high in (10.6\%). No significant differences were found based on gender, marital status, period of stay in the country of refuge or family life cycle. The study recommends employing evidence-based practice (EBP) with Syrian refugees suffering from PTSD, as growing evidence has emerged suggesting EBP is effective in treating PTSD. Key words: Post-Traumatic Stress- Elderly refugees

\section{Introduction:}

Ageing is a privilege, a societal achievement, and an inescapable reality of human existence. It is also a challenge, which will have an impact on all aspects of 21 st Century society. Singh \& Upadhyay 2014 pointed out that ageing is a complex process that involves physical, mental, spiritual and social processes that affect each person differently. The proportion of seniors is increasing more rapidly than all other age groups. Mental health conditions are a significant cause of morbidity and premature mortality for older adults (pp.61-70).

Worldwide, the proportion of elderly within countries' populations is increasing, with the greatest rise being in developing countries. There is also an increasing trend of interstate and societal conflict worldwide, along with conflict-induced forced migration taking place since the mid-2000s. The Virgincar, Doherty, Siriwardhana 2016 study showed that conflict-associated trauma significantly contributes to the subsequent development of mental disorders during post-displacement periods. Older adults affected by conflict and forced migration, mainly taking place in developing countries, may be particularly vulnerable to poor mental health due to 
other age-specific risk factors. The development of mental illness among forced migrant populations depends on a number of factors including the nature of trauma, number of traumatic events experienced, objective/perceived severity of trauma, age and gender (pp.889-896).

The mental health of forcibly displaced Syrian people following mass migration to neighboring countries remains a sensitive issue and the tragedy has mounted to a humanitarian crisis (Reed, Fazel, Jones, Panter-Brick, Stein, 2012, pp.250-265). The Syrian conflict has killed hundreds of thousands of people and forced 12.5 million people ( 6 out of 10 of the country's pre-war population) from their homes in the world's worst refugee crisis (Connor \& Krogstadl, 2016). Many surveys have underlined the high levels of distress Syrian refugees have endured since the conflict (Najaa et al 2016, p.78). The prevalence of mental health problems among refugees is estimated to be higher than in local populations as reported in the majority of research on the subject (Steel, Chey, Silove, Marnane, Bryant, Van Ommeren, 2009, pp.537-549).

Recent years have seen a consensus emerge on the treatment of post-traumatic stress disorder (PTSD) in the general population. The rate of PTSD among refugees is 10 times that of the general population (Crumlish, MRCPsych, O'Rourke, MRCPI, 2012) and many studies have shown a high frequency of PTSD among refugee populations. The diagnosis of PTSD is important because it represents a need for supportive measures, and treatment. Screening procedures have been devised in refugee populations; the Harvard Trauma Questionnaire (HTQ) is predominant because it has been validated across several refugee populations (So"ndergaard, Ekblad, Theorell., 2003, p.185).

PTSD does occur in older adults with similar symptoms as noted in younger adults. Interestingly, some salient differences in PTSD have been documented in older adults, such as differences in the natural course of the disorder, suggesting that the expression of PTSD may be influenced by factors such as natural changes brought about by aging and the societal zeitgeist at the time of trauma. In addition to a recent focus on the prevalence and symptom patterns of PTSD in older adults, a larger body of literature exists that examines related features of trauma exposure among older persons. These writings approach this issue from a non-psychiatric perspective, emphasizing clinical features, physical consequences, and social- 
psychological aspects of trauma exposure. Certainly, aging brings about unique changes that deserve consideration in the study of PTSD in older adults (Averill \& Beck, 2000, pp.133-156).

\section{Situation of Syrian refugees in Egypt}

Egypt hosts an estimated 250,000 to 300,000 Syrians who fled their country between 2011 and 2016 (only 117,350 were registered and received support from the United Nations as of October 2016). Syrian refugees are overrepresented among refugees in Egypt (World Health Organization, 2015). Egypt has not required that Syrians live in refugee camps, they mostly live in communities. However, according to World Health Organization (2015), Syrian refugees in Egypt are at a significantly higher risk of experiencing mental health problems (Kira \& Et al 2017, pp.177).

\section{Overview of PTSD among refugees}

Many studies on refugees suggest that traumatic events experienced by refugees are closely related to occurrences of posttraumatic stress disorder (PTSD). Kim, Yun, Jun, Park, 2018 found that North Korean refugees amongst subjects surveyed (a) demonstrated a high rate of current probable PTSD; and (b) demonstrated a higher frequency of repatriation experiences with a greater risk of PTSD symptoms. These findings suggest that particular types of trauma for populations with particular socio-demographic characteristics may be at a greater risk of PTSD.

Among Syrian refugees, Alpak et al 2015 found that the frequency of PTSD was $33.5 \%$. Through the binary logistic regression analysis, he calculated that the probability of having PTSD among Syrian refugees in his sample was $71 \%$ if they met the following criteria: female gender; diagnosed with psychiatric disorder in the past; have a family history of psychiatric disorder; and experienced two or more traumatic events (pp.45-50). Among 452 respondents, Kazoura et al 2017 found a lifetime prevalence of PTSD of $35.4 \%$, and a point prevalence of $27.2 \%$ (pp.41-47).

The Acarturk et al 2018 study reveals high rates of probable PTSD and depression among Syrian refugees and highlights vulnerabilities such as a great risk of women having psychopathology (pp.40-45). The rate of PTSD (34\%) is high according to the study of Kira et al 2017, even though they used a conservative approach in PTSD assessment (Cutoff criteria of a score $\geq 34$ ), which produced a high rate of elevated PTSD of $33.7 \%$, and also calculated probable 
clinical PTSD by the Diagnostic and Statistical Manual of Mental Disorders "DSM-IV-TR criteria" (pp.176-190).

Despite increasing international recognition of the specific needs and challenges older people face during times of crisis, this age group is still not receiving sufficient humanitarian and development response when it comes to health. Older Syrian refugees in Jordan are no exception. According to Help Age International, an estimated 77\% of all refugees over the age of 60 have specific needs related to mobility, nutrition and health care, and more than half of them report suffering from some form of psychological distress (Lupieri, 2018).

According to the DSM-IV; the diagnostic criteria for PTSD require the onset of characteristic symptoms following exposure to an extreme event and a reaction to that event that involves fear, helplessness, or horror (Criterion A1 and A2). Post traumatic symptoms must be present for more than one month and include at least one re-experiencing symptom (Criterion B), three avoidance/numbing symptoms (Criterion $\mathrm{C}$ ), and two hyperarousal symptoms (Criterion D) out of a total of 17 possible symptoms (Morina, Emmerik, Andrews, Brewin, 2014, pp.647-654).

The Vindbjerg et al 2016 study showed that refugees are known to have high rates of post-traumatic stress disorder (PTSD). Although recent years have seen an increase in the number of refugees from Arabic speaking countries in the Middle East, no study, to the best of the author's knowledge, has so far validated the construct of PTSD in an Arabic speaking sample of refugees. Responses to the Harvard Trauma Questionnaire (HTQ) were obtained from 409 Arabic-speaking refugees diagnosed with PTSD and undergoing treatment in Denmark. Confirmatory factor analysis was used to test and compare five alternative models. Results showed all four- and five-factor models provided sufficient fit indices. However, a combination of excessively small clusters, and a case of mistranslation in the official Arabic translation of the HTQ, rendered results of two of the models inadmissible. A post hoc analysis revealed that a simpler factor structure is supported, once local dependence is addressed. Overall, the construct of PTSD is supported in this sample of Arabic-speaking refugees. Apart from pursuing maximum fit, future studies may wish to test simpler, potentially more stable models, which allow a more informative analysis of individual items. 
Research has suggested that PTSDs among refugees are higher than in local populations, yet, there is a gap in the study of PTSD in older refugees compared with other categories of refugees. Salient differences in PTSD have been documented in older adults; and it is expected that there would be differences in PTSD among elderly refugees compared to other categories of refugees. By employing Harvard Trauma Questionnaire (HTQ) across several refugee populations, this study aims to diagnose post-traumatic stress among elderly Syrian refugees, and to test the following hypotheses;

1. There are different levels of PTSD among elderly Syrian refugees living in Egypt.

2. There are different symptoms are experienced by elderly Syrian refugees living in Egypt.

3. There are significant differences in levels of PTSD among elderly Syrian refugees living in Egypt based on the following variables: stages of aging, gender, social statues, period of stay in refuge country, and family life cycle.

\section{Methodology}

The current study was based on the Harvard Trauma Questionnaire Part IV (HTQ: Mollica et al, 1992), (Iraqi version). The HTQ assesses both DSM-IV symptoms and culture specific symptoms associated with PTSD. The scale yields both a PTSD diagnosis according to DSM-IV criteria and a measure of PTSD symptom severity. The HTQ asks respondents how much each symptom has bothered them in the last week. The 45 items are answered on a fourpoint Likert-type scale ('not at all' (1), 'a little' (2), 'quite a bit' (3), and 'all the time' (4). The summed scores provide a score for symptom severity. The items are divided into three subscales that correspond to the three main symptom groups of PTSD: reexperiencing, avoidance, and arousal. It should be noted that items (41-45) included both indigenous and Western constructs. The HTQ reports high estimates of reliability and concurrent validity for each of the subscales and the scale as a whole (0.564). Socio-demographic characteristics of the participants were assessed on a brief structured questionnaire (Table 1). All participants were informed that their answers and the results of this study would be confidential. Those who agreed to participate gave written informed consent. 
The study population consisted of elderly Syrian refugees $(>60$ years old) living in Egypt due to the recent conflicts in Syria. Access to subjects was through the UN Refugee Agency (UNHCR- EGYPT), and community center collaborators, as shown in the following table:

\begin{tabular}{|c|c|c|c|}
\hline \multicolumn{2}{|c|}{ Agencies } & $\overline{\mathrm{N}}$ N. & \% of sample \\
\hline \multicolumn{4}{|c|}{ " UNHCR } \\
\hline \multicolumn{2}{|c|}{ Registration center, Alexandria } & 29 & 61.7 \\
\hline \multicolumn{4}{|c|}{$\begin{array}{l}\text { Community center } \\
\text { collaborators with UNHCR }\end{array}$} \\
\hline 1 & FARD foundation & 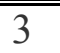 & 6.4 \\
\hline 2 & Caritas & 10 & 21.3 \\
\hline 3 & $\begin{array}{l}\text { United Nations Population } \\
\text { Fund (UNFPA- Egypt) }\end{array}$ & $\overline{5}$ & 10.6 \\
\hline \multicolumn{2}{|r|}{$\bar{\sum}$} & 47 & 100 \\
\hline
\end{tabular}

Results:

\section{Demographic of elderly Syrian refugees in Egypt}

The demographic characteristics of the population (Table 1) shows that $91.5 \%$ were aged between 60 to 70 years, i.e. the first stage of aging, $6.4 \%$ were aged between 71 to 80 years i.e. the second stage of aging, $2.1 \%$ were over 80 years, $64.8 \%$ were male, and $36.2 \%$ were female. As for marital status of the population, $68.1 \%$ were married, $17.1 \%$ were widows, and $14.9 \%$ were divorced / separated. $64.8 \%$ of the population has been living in Egypt for more than 36 months, $19.1 \%$ have been living in Egypt for 25 to 36 months, and $17.1 \%$ have been living in Egypt for 13 to 24 months. In the family life cycle, 34\% were in post-parental status, 32\% separated husband / wife, $27.6 \%$ parenting, and $6.4 \%$ couples without children. The demographic characteristics of the study sample shows that the majority were settled in Egypt for more than 2 years, and that although many were over 60 years of age, $27.6 \%$ of them were in the parenting stage where their sons / daughters have not yet formed families of their own and were still living with them.

\section{Levels of PTSD among elderly Syrian refugees in Egypt}

Table 2 shows that $100 \%$ of subjects are suffering from posttraumatic stress disorder and the level of disorder is average in $89.4 \%$ of the sample, and high in $10.6 \%$. Symptoms have been chronic. The American Association of Psychiatric Psychiatry Association has indicated that this form shows symptoms immediately after the trauma but may extend to six months after its occurrence. This was the case 
with all subjects whose stay in Egypt exceeded one year. Consequently support the validity of the first hypothesis of this research" There are different levels of PTSD among elderly Syrian refugees living in Egypt".

\section{PTSD symptoms among elderly Syrian refugees in Egypt:}

3.1. The most severe symptoms of post-traumatic stress disorder in elderly Syrian refugees:

Results shown in table 3 regarding the most severe symptoms of post-traumatic stress disorder among elderly Syrian refugees residing in Egypt suggests that those symptoms were close to $90 \%$, ranging from 89.89 to $81.91 \%$. The most severe manifestation was their feeling that they have no one to rely upon but God $(89.89 \%)$, difficulty paying attention, spending time thinking why God is making them go through such events $(88.30 \%)$, constant feeling of fatigue, feeling a need for revenge $(87.77 \%)$, feeling as though they are split into two people and one is watching what the other is doing, loss of hope $(87.77) \%$, feeling jumpy, easily startled, difficulty sleeping and feeling that they have fewer skills than they did before $(85.64 \%)$, various signs of forgetfulness and powerless to help others $(85.11 \%)$, and finally difficulty concentrating $(82.45 \%)$ and feeling constantly on guard $(81.91 \%)$.

\subsection{Average symptoms of post-traumatic stress disorder in elderly Syrian refugees}

Results shown in table 4 regarding average symptoms of posttraumatic stress disorder in elderly Syrian refugees residing in Egypt suggest that these symptoms range from 80.85 to $64.36 \%$. It included recurrent nightmares, feeling irritable or having outbursts of anger, and Dayeg in 80.85 to $80.32 \%$, recurrent thoughts or memories of the most hurtful or terrifying events, troubled by bodily pain or physical problems, the feeling as if they don't have a future, and that others are not able to understand what happened to them, feeling as though the event is happening again, avoiding activities that remind them of the hurtful event, sudden emotional or physical reaction when reminded of the most hurtful events, feelings of heart contraction (Qalbak maqboud (unable to feel emotions, emotional fatigue) Nafseetak ta'abana (feeling detached or withdrawn from people, feeling guilty for having survived, shortness of breath and suffocation) Nafsak Deeyega and Makhnouk (ranging from 79.79 to 70.74\%). Finally, the distrust of others in $67.02 \%$, and the feeling of humiliation in $64.36 \%$ of subjects. 


\subsection{The least severe post-traumatic stress disorder among elderly Syrian refugees:}

Results shown in table 5 regarding the least severe post-traumatic stress disorders among elderly Syrian refugees in Egypt suggest that these manifestations ranged from 61.17 to $56.91 \%$. These symptoms were having difficulty dealing with new situations, less interest in daily activities, feeling unable to make daily plans, inability to remember parts of the most hurtful events, and avoiding thoughts or feelings associated with the hurtful events. It seems that the lack of severity of these symptoms could be attributed to their correlation with daily life activities, which are indispensable for the continuation of life in the country of shelter.

Results also showed lack of a number of post-traumatic stress disorder symptoms among elderly Syrian refugees in Egypt in 40.43 to $35.11 \%$ of subjects, these symptoms included finding out or being told by other people that you have done something that you can't remember, feeling that someone you trusted betrayed you, feeling that you are the only one who suffered these events, blaming oneself for things that have happened, feeling others are hostile to you, feeling ashamed of the hurtful or traumatic events that have happened to you, and feeling that you are a jinx to yourself and your family.

Consequently support the validity of the second hypothesis of this research" There are different symptoms are experienced by elderly Syrian refugees living in Egypt".

4. PTSD among elderly Syrian refugees according to variables: stages of aging, gender, social status, period of stay in refuge country, family life cycle

Table 6 shows there are no significant differences in PTSD among elderly Syrian refugees according to variables: stages of aging, gender, marital status, period of stay in refuge country, and family life cycle. Going through the refugee experience and living the Syrian crisis with all its horrific incidents and consequences have caused the same symptoms in all Syrian elderly refugees. Age seems to be the decisive factor in causing PTSD in the aging stage while other factors were stabilized. Consequently support the invalidity of the third hypothesis of this research" There are significant differences in levels of PTSD among elderly Syrian refugees living in Egypt based on the following variables: stages of aging, gender, social statues, period of stay in refuge country, and family life cycle". 


\section{Discussion}

Results show that all subjects of the study, who were elderly Syrian refugees residing in Egypt, suffered from post-traumatic stress disorder, and that the level of PTSD was average in $89.4 \%$ of the sample and high in 10.6\%, even though their stay in Egypt was not in camps or similar concentrated dwellings. It was expected that the rate of post-traumatic stress disorder in refugees living in an Arab community, with almost the same characteristics, would be low or at least the level of disturbance would be low, yet, the refugee experience caused by the Syrian crisis seems to have had a profound impact on the Syrian elderly, as is the case with other groups. These results are in line with the findings of several studies on posttraumatic stress disorder in different groups of Syrian refugees. For instance, results of the Al-Adinat 2012 study showed increased PTSD symptoms in a sample of (485) Syrian refugee children at Za'atari camp in Jordan. The Al-Gharabia 2014 study found that the level of post-traumatic stress disorder was average in a sample of (500) male and female teenagers in al-Za'atari camp, and the Al-Qada 2016 study results found increased PTSD levels in a sample of 490 Syrian refugees living in Ajloon Governorate in Jordan.

This is also in line with research findings that have addressed the psychological and mental health of older refugees in different cultures. Tran, 1991 concluded that age has a statistically significant relationship indicating that older refugees had a poorer sense of adjustment than their younger counterparts (Tran, 1991). Roemer, 1993 concluded that life satisfaction levels of elderly refugees have a significant relationship with social support, or acculturation (Roemer, 1993). Chou, 2000 also concluded that nearly all of the women had depression scores that indicated probable major depression (Chou, 2000). Moon, 2010 suggests that the well-being and process of adjustment of immigrant elders is affected by their immigration histories, cultural norms and values, and socio-economic backgrounds (Moon, 2010). Experiences of aging refugees or immigrants are significantly different from elders who have not experienced international migration. Multiple meanings of aging in place that go beyond the ability to remain in one's preferred geographic location, maintenance of independence and autonomy, and attachment and meanings assigned to place. One's sense of place was defined geographically, socially, or culturally, and often created challenges for these elders (Lewis, 2009). One of the main elements in defining 
aging is the inclination towards the place. In addition to the findings of other research investigating different refugee issues, another aspect of the findings of this research includes the existential crisis of elderly refugees, existential needs for feelings of belonging, roots, continuity, authenticity, efficacy, self-worth, familiarity, and stability (Morozova, 2008), and health issues (Handlos et al, 2015).

The findings show that symptoms of post-traumatic stress disorder among the study subjects are chronic, given that they extend beyond six months after trauma occurs, and will require further indepth investigations for precise explanations of each case. Much of the research into refugee issues perhaps partly explains why this condition is chronic.

The experience of refugees seems to have a profound impact on those who have been living in camps or communities, regardless of sex, age, marital status or family life cycle. The experience the Syrian war refugees have had has led to a high level of post-traumatic stress disorder in this population in general, and the elderly in particular. This may be attributed to the nature and characteristics of this age group, and especially to those who have lived in their home for over 60 years who feel they may die before being able to return home, in light of prolongation, complexity and worsening of the Syrian crisis. Carrion, 2015 suggests that it does not look like refugees will be able to return to Syria any time soon; no matter how hard life becomes (Carrion, 2015).

Baban \& Ilcan, 2017 suggest that Syrian refugees are facing pathways to precarity, differential inclusion, and negotiated citizenship rights (Baban \& Ilcan, 2017). Memisoglu, 2016 suggests that, in Syrian refugee and asylum policy, the mass influx of Syrian refugees has become an issue of particular concern due to the complex interplay between its security, humanitarian and socio-economic dimensions and the multifaceted relationship between the growing number of state and non-state institutions (Memisoglu, 2016). Toğ ralKoca, 2016 discussed Syrian refugees: From guests to enemies? (Toğ ralKoca, 2016), and Fakih, 2016 discussed the impact of Syrian refugees on the labor market in neighboring countries (Fakih, 2016).

The burden of neuropsychiatric disorders in refugees is likely to be high, but little has been reported on the neuropsychiatric disorders that affect Syrian refugees in a country of first asylum (McKenzie et al, 2015). Strong et al, 2015 concluded that older 
refugees from Syria are a highly vulnerable population needing health surveillance and targeted assistance. Programs assisting vulnerable populations may concentrate services on women and children, leaving the elderly overlooked (Strong et al, 2015). Abo-Hilal, 2014 in his "Beyond survival" article, stressed the significance of providing psychological services for Syrian refugees (Abo-Hilal, 2014). Thus, there are various factors that make refugees vulnerable to the development of post-traumatic stress disorder, including increased duration of the traumatic event, the number of times the refugee suffers a traumatic event, the severity of the trauma, and the lack of support and assistance during or after the refugee period. However, those who develop a post-traumatic stress disorder are not direct victims of the event, but rather those who have witnessed the event and its destructive aftermath.

Results show that the most severe post-traumatic stress disorder among the elderly Syrian refugees residing in Egypt was represented in several aspects that include cognitive, emotional, social, behavioral, physical, and spiritual manifestations. The cognitive aspect featured in the difficulty of maintaining attention, frequent forgetfulness, and difficulty of concentration. The emotional featured in their sense of division, feeling a need for revenge, and their loss of hope. The social was represented in the inability to rely on others and the inability to help them, feeling that they have less skill than they did before. The behavioral aspect featured in feeling jumpy and easily startled, and constantly feeling on guard, while the physical aspect featured in a constant feeling of fatigue. The most intense manifestation was spiritual, featured in questioning why God is making them go through such events. A more holistic consideration of the issue that includes the unique psychological, cognitive, behavioral, social, physical, and spiritual characteristics of this stage in human life, asylum and refugee issues, and the severity of post-traumatic stress disorder among Syrian refugees, may result in more appreciation of the suffering of elderly Syrian refugees residing in Egypt and their urgent need for clinical interventions. In general, it may be stressed that aging has a distinguished psychological, cognitive, behavioral, physical and spiritual trait in human life, and that the severity of PTSD manifestations experienced by elderly Syrian refugees in Egypt may call for urgent clinical interventions. 
The average manifestations experienced by elderly Syrian refugees included a great presence of re-experience, recurrent thoughts or memories of the most hurtful or terrifying events, feeling as though the event is happening again, and having physical and emotional reactions when remembering traumatic events. It is coupled with several behavioral aspects, such as feeling irritable or having outbursts of anger and feeling Dayeg. Psychic manifestations represented in a feeling of Inqibad Al-Qalb, an inability to feel emotion, emotional fatigue, feeling detached or withdrawn from people, feeling guilty for having survived, and feeling humiliated. Physical manifestations showed in troubling bodily pain or problems such as shortness of breath and feelings of suffocation. An important variable has also emerged, that is the feeling that they have no future, perhaps such a variable comes with age and refugee status, and the continuation of the Syrian crisis, and may explain why the symptoms of posttraumatic stress disorder in subjects are chronic.

\section{Relations between symptoms of PTSD and social life of elderly Syrian refugees:}

Exceptional situation, it has had an impact on the various dimensions of the life of elderly refugees. Brunet\& Caron 2015 showed Quality of life were particular impairments for specific domains dependent on PTSD diagnosis, with remitted and ongoing PTSD showing significantly different quality of life for subscales such as daily life/social. According to the results of McMillan \& Et al 2017 study, Individuals with comorbid PTSD demonstrated an elevated risk of lifetime suicide attempts and substantially lower levels of physical and mental quality of life. The psychosocial consequences of PTSD comorbidity are substantial. Clients may benefit from early interventions to remediate social distress and improve support networks before more intensive psychotherapeutic interventions. Elliott TR. \& ET al 2016 revealed that resilience significantly predicted posttraumatic stress disorder (PTSD), depression, quality of life, and social support over time. Lauren M \& Et al 2018 showed, while poor social connectedness is often a consequence of living with posttraumatic stress disorder (PTSD) symptoms, little is known about whether PTSD symptom clusters may be uniquely related to different aspects of social connectedness. A large proportion distress related to problems getting along with others $(66.2 \%)$ and few days of contact with supportive people (43.5\%). High rates of difficulties in social connectedness and distinct associations among these difficulties with 
emotional numbing, dysphoric arousal, and anxious arousal symptoms. Social support is a robust correlate of posttraumatic stress disorder (PTSD) symptoms. Shallcross, \& Et al 2016 suggested PTSD-specific symptom dimensions may both erode and be influenced by social support, whereas general psychological distress erodes social support. So, Stressful life events, social support, and the number of traumatic events were each separately associated with the risk for PTSD. The number of traumatic events, stressful life events, and social support resulted in an increased risk for PTSD. High-risk individuals (a large number of traumatic events, high level stressful life events, and low social support) had a 3.26- fold increased risk of developing PTSD compared to low-risk individuals (Lian \& ET al, 2014).

Therefore, according to the results of previous studies, PTSD symptoms are associated with lower levels of quality of life c poor social connectedness 'daily life/social problems, a large proportion distress related to problems getting along with others ‘High rates of difficulties in social connectedness and distinct associations among these difficulties with emotional numbing, dysphoric arousal, and anxious arousal symptoms. So, social support is a robust correlate of posttraumatic stress disorder (PTSD) symptoms. Clinical social work should focus its practice on social support networks for elderly Syrian refugees, that available in Egyptian community, such as NGOs, Human rights organizations, Syrian association, and Community support, psychosocial support, case management, problem-solving support, counseling, referral, emergency response for all refugees.

\section{Clinical social work practice with elderly Syrian refugees suffering from PTSD:}

Joseph \& Murphy 2014 showed three reasons to deserve PTSD greater attention in social work practice. First, social work professionals in the various settings in which they work are often confronted with clients whose problems have their roots in some form of traumatic experience. Second, social work is able to bring a muchneeded social and relational approach which recognises the multitude of ways in which people are affected by trauma. While there is a need for one-to-one psychotherapy services, trauma affects not only the individual, but the individual within their social context. Third, as well as the core symptoms of PTSD described above, PTSD has a variety of knock-on effects. Ordinary life falls apart and there are often associated problems of depression, anxiety, substance use. 
In professional practice with Syrian refugees suffering from PTSD, social workers should assess and intervene as follows:

\section{Assessment:}

I. The main symptom groups of PTSD: re-experiencing, avoidance, and arousal

II. The Sub-symptoms of PTSD: Emotional, Cognitive, Social, Behavioral, and Spiritual

III. The Levels of PTSD: Low, Medium, High

IV. The Term time of PTSD: temporary, chronic

V. The multitude ways in which refugees are affected by trauma

VI. Effects of PTSD on social performance, Social role, and social problems

\section{Intervention:}

I. Path of symptoms, Focus on the person

II. Path of symptoms effects, Focus on the social environment

The central tenet of cognitive behavioral therapy is that it is not just what happens to us that affects our mood and behavior but how we interpret such events and our more general beliefs about the world. This each influences our feelings, motivations, and actions

Bennett 2002, P 93), It mean "If people think Right they will Do Right" (Tavris \& Wade 1997, P. 266). The cognitive dimension considers 'how behavior is guided by the perceptions and analysis of what we see' and how 'irrational thoughts or disturbances in perception lead us to process our view of the world incorrectly' (Milner \&O Byrne 2002, P 169). Ellis has devised an A-B-C theory of personality functioning. In this case, A refers to the activating event, which may be some action or attitude of an individual, or an actual physical event. $\mathrm{C}$ is the emotional or behavioral consequence of the event, the feelings or conduct of the person experiencing the event. However, for Ellis A does not cause $\mathrm{C}$. between $\mathrm{A}$ and $\mathrm{C}$ come $\mathrm{B}$, the person's beliefs about the event. Ellis contends that events are always mediated by beliefs, and that the emotional consequences of events are determined by the belief about the event rather that the event itself (Mcleod 2003, p 135).

So, in cases of elderly Syrian refugees who suffering from PTSD, We note according Ellis "A-B-C theory" to the following:

- A refers to the activating event (Trauma). 
- $\mathrm{C}$ is the emotional, cognitive, social, behavioral, and spiritual consequence of the event, that appear in the main symptom groups of PTSD: re-experiencing, avoidance, and arousal.

- A does not cause C.

- B comes between A and C, the person's beliefs about the event. - A was end, C is existing, because B "the elderly Syrian refugees' beliefs" about the refuge in all its circumstances, is Continuous.

- In professional intervention, clinical social worker focuses on B and its effects on social life.

\section{Proposed social work interventions with elderly Syrian refugees who suffer from PTSD}

In the light of the Results of the study about the manifestations of post-traumatic stress disorder, that include cognitive, emotional, social, behavioral, physical, and spiritual manifestations, it is important to point out the following:

- Clinical social work practices are an urgent necessity with elderly Syrian refugees.

- While the previous studies were conducted in the Syrian refugee camps in Jordan, Ajloun and Zaatari, the current study investigated the Syrian refugees living in the Egyptian society where there are no camps for the Syrians in Egypt. Although the results of the previous and the current studies show no clear differences between different Syrian refugees according to age in PTSD, those refugees living in a society are suffering from posttraumatic stress disorder just like those living in camps and even the disruption is of a chronic form as well as the characteristics of aging. This makes it a different matter for clinical social workers.

- The clinical social workers should take into account the exceptional situation of "old-age-chronic PTSD" in their future practice with the elderly Syrian refugees, especially in their social, health, psychological and economic conditions, as well as the multifaceted relationship between governmental and nongovernmental institutions concerned with the Syrian refugees in Egypt.

- - The mental health of the elderly in general and of refugees in particular is one of the most important issues facing clinical social work.

- - The importance of developing a new perspective for the practice of clinical social work with the Syrian refugees suffering from 
Post-Traumatic Stress Disorder. This perspective goes beyond the traditional practice and is based on professional-impact therapeutic techniques with post-traumatic stress disorder in light of the following :

1. Cognitive behavioral therapy has developed a kind of therapy to deal with trauma effects. This treatment of exposure therapy is specifically developed to treat post-traumatic stress disorder effectively.

2. Psychotherapy has developed a kind of therapy which has been specially adapted to treat PTSD". The most important one is the "Psychodynamic Imaginative Trauma Therapies PITT" which is primarily used to treat complex PTSD.

\section{Conclusions and recommendations:}

We are facing an exceptional situation. An age group of refugees with certain characteristics, suffering from chronic average to high post-traumatic stress disorder, regardless of sex, marital status, duration of stay in the country of shelter, or family life cycle. All the specifics of the situation should develop indicators for clinical practitioners in their professional practice with elderly Syrian refugees suffering from PTSD. The clinical practice with elderly Syrian refugees suffering from PTSD should rely on evidence-Based Practice (EBP) as growing evidence has emerged suggesting EBP effectiveness in treating PTSD as shown in the following table:

\begin{tabular}{|c|c|c|c|c|c|c|}
\hline \multirow[b]{2}{*}{ Variables } & \multicolumn{6}{|c|}{ Content type } \\
\hline & $\begin{array}{l}\text { Journal } \\
\text { article }\end{array}$ & $\begin{array}{c}\text { Dissertation / } \\
\text { Thesis }\end{array}$ & Book & $\begin{array}{l}\text { Book } \\
\text { chapter }\end{array}$ & Publication & Total \\
\hline $\mathrm{CBT}+\mathrm{PTSD}$ & 7138 & 2173 & 727 & 719 & 239 & 11,458 \\
\hline $\begin{array}{l}\text { CBT+ PTSD+ } \\
\text { Refugees }\end{array}$ & 746 & 174 & 70 & 62 & 45 & 1,105 \\
\hline $\begin{array}{l}\text { CBT+ PTSD+ } \\
\text { Refugees }+ \\
\text { older person }\end{array}$ & 246 & 90 & 62 & 26 & 15 & 433 \\
\hline
\end{tabular}

There is also growing evidence to explain post-traumatic stress disorder (PTSD) according to a cognitive process. It seems that when an individual is exposed to traumatic events, those events are recognized as new and strange information from the cognitive scheme of the individual because they are not included in that scheme. Individuals are often not prepared to confront these events, because they are events outside the normal human experience and therefore are not expected to occur. When they occur, the individual does not have the ability, the means, or a way to deal with them, and thus threaten the individual and disorders his or her behavioral system. 


\section{References:}

Abo-Hilal, M., Yousef, O.S. (2014) Beyond survival: A brief description of psychological services for: Syrian refugees, Peace and Conflict, 20 (3), pp. 334-336

Acarturk, c., Cetinkaya,m., Senay, I., Gulen, B., Aker, T., \& Hinton, D. (2018) Prevalence and Predictors of Posttraumatic Stress and Depression Symptoms among Syrian Refugees in a Refugee Camp, Journal of Nervous and Mental Disease, 206(1), DOI: 10.1097/NMD.0000000000000693

Al- Gharaibeh, Mahmoud (2014) Post-traumatic stress disorder and coping strategies among adolescents at Al- Zatare Refugee Camp, Master thesis, Yarmouk University - Gordon

Al-Adainat, Khaldoun (2012) PTSD among children and adolescents in the Za'tari refugee camp in Jordan, Journal of Culture and Development, Cairo, 13 (58)

Alpak, G., Unal, A. , Bulbul,F., Sagaltici, E. , Bez,Y., Altindag,A., Dalkilic,A. \&Savas,A.(2015) Post-traumatic stress disorder among Syrian refugees in Turkey: A cross-sectional study, Psychiatry Clinical Practice; 19. Healthcare, DOI: 10.3109/13651501.2014.961930

ALquda, Ayat (2015) The level of post - traumatic stress disorder among a sample of Syrian Refugee residing in Ajloun, Master thesis, Yarmouk University - Gordon

Averill,P. \& Beck,G.(2000) Posttraumatic Stress Disorder in Older Adults: A Conceptual Review, Journal of Anxiety Disorders, 14(2), pp. 133 156

Baban, F., Ilcan, S., Rygiel, K. )2017) Syrian refugees in Turkey: pathways to precarity, differential inclusion, and negotiated citizenship rights, Journal of Ethnic and Migration Studies, 43 (1), pp. 41-57. DOI: 10.1080/1369183X.2016.1192996

Bennett, P. (2002). Behavioral and cognitive Behavioral Approaches to substance Misuse treatment, In: T. Petersen., \& A, McBride. (Eds): working with substance misusers" A Guide to theory and practice" (P 93). NY: Routledge.

Brunet, Alain \& Caron, Jean (2015) Domains of quality of life and social support across the trauma spectrum Eva Monson, Soc Psychiatry Psychiatr Epidemiol DOI 10.1007/s00127-015-1029-y.

Carrion, D. (2015) Jordan and Syrian Refugees: Avoiding the Worst Case Scenario, Middle East Law and Governance, 7 (3), pp. 319-335. DOI: 10.1163/18763375-00703004

Chou, Jaimie Sokheng (2000) the relationship between social support and depression among Cambodian (Khmer) elderly women refugees, California State University, Long Beach, M.S.W

Connor, P. \&Krogstadl, M.(2016). About six-in-ten Syrians are now displaced from their homes. PEW Research Center, Retrieved from 
http://www.pewresearch.org/fact-tank/2016/06/13/about-six-in-ten-syriansarenow-

Crumlish,N., MRCPsych,M, O’Rourke,K., MRCPI,M.(2012) A Systematic Review of Treatments for Post-Traumatic Stress Disorder Among Refugees and Asylum-Seekers, Journal of Nervous and Mental Disease , 198, (4).

DOI: $10.1080 / 13629395.2016 .1189479$

Elliott TR. \& ET al (2016) Resilience and Traumatic Brain Injury among Iraq/Afghanistan War Veterans: Differential Patterns of Adjustment and Quality of Life, Journal of Clinical Psychology, 73 (9), pp. 1160-1178

Fakih, A., Ibrahim, M.(2016)The impact of Syrian refugees on the labor market in neighboring countries: empirical evidence from Jordan,) Defence and Peace Economics, 27 (1), pp. 64-86. DOI:

10.1080/10242694.2015.1055936

Handlos, L.N., Olwig, K.F., Bygbjerg, I.C., Kristiansen, M., Norredam, M.L. (2015) Return migration among elderly, chronically ill bosnian refugees: Does health matter? International Journal of Environmental Research and Public Health, 12 (10)

Joseph, Stephen \& Murphy, David (2014) Trauma: A Unifying Concept for Social Work, British Journal of Social Work, 44

Kazoura,F. , Zahreddinea,N., Maragela,M., Almustafaa, M., Soufiac, M., Haddada, R., Richaa, S. (2017) Post-traumatic stress disorder in a sample of Syrian refugees in Lebanon, Comprehensive Psychiatry 72.

Kim, E., Yun, M., Jun, J., Park, W. (2018) Pre-migration Trauma, Repatriation Experiences, and PTSD among North Korean Refugees, Journal of Immigrant and Minority Health, doi.org/10.1007/s10903-018-0742-5

Kira,I., Shuwiekh,HRice,K., Al Ibraheem,B., Aljakoub,J.(2017). A Threatened Identity: The Mental Health Status of Syrian Refugees in Egypt and Its Etiology, IDENTITY: AN INTERNATIONAL JOURNAL OF THEORY AND RESEARCH, 17(3) doi.org/10.1080/15283488.2017.1340163

Lauren M \& Et al (2018) The Unique Roles of Emotional Numbing and Arousal Symptoms in Relation to Social Connectedness Among Military Veterans in Residential Treatment for PTSD, journal Psychiatry: Interpersonal and Biological Processes, 81, 2018

Lewis, D.C. (2009) Aging out of place: Cambodian refugee elders in the United States, Family and Consumer Sciences Research Journal, 37 (3) DOI: $10.1177 / 1077727 X 08330684$

Lian, Yulong\& ET al (2014) the relationship between glucocorticoid receptor polymorphisms, stressful life events, social support, and posttraumatic stress disorder, BMC Psychiatry, doi: 10.1186/s12888-014-0232-9

Lupieri, S. (2018) Syrians in displacement: The neglected health needs of older Syrian refugees in Jordan, www.fmreview.org/syria 


\begin{tabular}{||lcc||}
\hline \multicolumn{2}{|l|}{ Egyptian Journal of Social Work (EJSW) } & http://ejsw.journals.ekb.eg \\
Print ISSN: 2356-9204 & Online ISSN: 2356-9212 & Vol 8, Issue 1, June 2019 \\
\hline \hline
\end{tabular}

McKenzie, E.D., Spiegel, P., Khalifa, A., Mateen, F.J. (2015) Neuropsychiatric disorders among Syrian and Iraqi refugees in Jordan: A retrospective cohort study 2012-2013, (Conflict and Health, 9 (1) DOI: 10.1186/s13031-015-0038-5

Mcleod, J. (2003). From Behaviorism to constructivism: the cognitive - Behavioral Approach to counseling, In, J, Mcleod (Ed). An introduction to counseling (3rd Ed), (Pp. 132-135), Maidenhead: Open University press.

McMillan KA, Asmundson GJG, Sareen J (2017) Comorbid PTSD and Social Anxiety Disorder: Associations with Quality of Life and Suicide Attempts, the Journal of Nervous and Mental Disease, 205 (9), pp. 732-737.

Memisoglu, F., Ilgit, A(2016) Syrian refugees in Turkey: multifaceted challenges, diverse players and ambiguous policies, Mediterranean Politics, pp. 1-22.

Milner, J., \&O’Byrne, P. (2002).Assessment in social work (2nd Ed), (P 169), NY: Palgrave MacMillan.

Moon, A., Rhee, S. (2010) Immigrant and Refugee Elders Handbook of Social Work in Health and Aging, Oxford University Press. DOI: 10.1093/acprof:oso/9780195173727.003.0017 Morina,N., Emmerik,A., Andrews,B., Brewin,C. (2014). Comparison of DSM-IV and Proposed ICD-11 Formulations of PTSD among Civilian Survivors of War and War Veterans, Journal of Traumatic Stress, 27, 647654.

Morozova, Isabella (2008) Search for home in a subsidized housing setting: Existential crisis of Russian elderly refugees, University of Denver, Ph.D.

Najaa,W., Aoun,M., El Khoury,E., BouAbdallah,E., Haddad,R.(2016). Prevalence of depression in Syrian refugees and the influence of religiosity, Comprehensive Psychiatry, 68

Reed, V., Fazel, M., Jones, L., Panter-Brick, C., Stein, A. (2012) mental health of displaced and refugee children resettled in low-income and middle-income countries: risk and protective factors, Lancet, 379(9812), 250-265.

Roemer, Patrick (1993) Life satisfaction levels of elderly Vietnamese refugees and their participation in informal community support networks, California State University, Long Beach, (M.S.W).

Shallcross, Sandra L. \& Et al (2016) Social Causation Versus Social Erosion: Comparisons of Causal Models for Relations between Support and PTSD Symptoms, Journal of Traumatic Stress, 29, 167-175

Shoeb, M.,Weinstein, H., \&Mollica, R (2007). The Harvard trauma questionnaire: adapting a cross-cultural instrument for measuring torture, trauma and posttraumatic stress disorder in Iraqi refugees, International Journal of Social Psychiatry, 53(5). DOI: 10.1177/0020764007078362 


\begin{tabular}{||lcc||}
\hline Egyptian Journal of Social Work (EJSW) & http://ejsw.journals.ekb.eg \\
Print ISSN: $2356-9204$ & Online ISSN: 2356-9212 & Vol 8, Issue 1, June 2019 \\
\hline \hline
\end{tabular}

Singh, R \&Upadhyay, A (2014) Mental Health of Elderly People, Journal of Psychosocial Research, 9 (1)

So"ndergaard H., Ekblad S., Theorell T.(2003) Screening for posttraumatic stress disorder among refugees in Stockholm, Nord J Psychiatry, 57.

Steel, Z., Chey, T., Silove, D., Marnane, C., Bryant, A., Van Ommeren, M (2009) Association of torture and other potentially traumatic events with mental health outcomes among populations exposed to mass conflict and displacement: a systematic review and meta-analysis, Jama, 302(5), 537-549.

Strong, J., Varady, C., Chahda, N., Doocy, S., Burnham, G. (2015) Health status and health needs of older refugees from Syria in Lebanon, Conflict and Health, 9 (1) DOI: 10.1186/s13031-014-0029-y

Tavris, C \& wade, C. (1997) Psychology in perspective (2nd Ed), (P. 266), NY: An Imprint of Addison Wesley Longman

Toğ ralKoca, B. (2016) Syrian refugees in Turkey: From guests to enemies?, New Perspectives on Turkey, 54, pp. 55-75. DOI: 10.1017/npt.2016.4

Tran, T.V. (1991) Family living arrangement and social adjustment among three ethnic groups of elderly Indochinese refugees, International Journal of Aging and Human Development, 32 (2).

Vindbjerg, E , Carlsson,nJ, Mortensen,E, Elklit,A\&Makransky,G(2016) The latent structure of post-traumatic stress disorder among Arabic-speaking refugees receiving psychiatric treatment in Denmark, BMC Psychiatry, DOI 10.1186/s12888-016-0936-0

Virgincar, A., Doherty, S., Siriwardhana, C. (2016). The impact of forced migration on the mental health of the elderly: a scoping review, International Psychogeriatric, 28(6) Doi: 10.1017/S1041610216000193

WHO (2015) . Syria Crisis- Egypt, Retrieved from http://www.who.int/hac/crises/syr/syria_crisis

Y1ld1z, A., Uzgören, E. (2016) Limits to temporary protection: noncamp Syrian refugees in İzmir,Turkey, Journal of Southeast European and Black Sea, 16 (2), pp. 195-211. DOI: 10.1080/14683857.2016.1165492 


\section{Egyptian Journal of Social Work (EJSW) http://ejsw.journals.ekb.eg}

Print ISSN: 2356-9204 Online ISSN: 2356-9212 Vol 8, Issue 1, June 2019

Table.1: Demographic data:

\begin{tabular}{|c|c|c|c|c|c|}
\hline variables & $\overline{\mathbf{N}}$ & $\%$ & variables & $\overline{\bar{N}}$ & $\%$ \\
\hline Age & & & \multicolumn{3}{|c|}{$\begin{array}{l}\text { Period of stay in refuge } \\
\text { country }\end{array}$} \\
\hline 600-70 & 43 & 91.5 & $0-12$ & ב- & 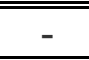 \\
\hline $71-80$ & 3 & 6.4 & $13-24$ & 8 & 17.1 \\
\hline 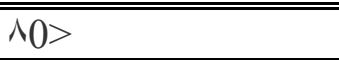 & 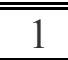 & 2.1 & $25-36$ & 9 & 19.1 \\
\hline Gender & & & \multicolumn{3}{|l|}{ Family life cycle } \\
\hline Male & 17 & 36.2 & Parental stage & 13 & 27.6 \\
\hline Female & 30 & "64.8 & $\begin{array}{l}\text { Post- Parental } \\
\text { stage }\end{array}$ & 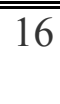 & 34 \\
\hline Marital status & & & Couple(without) & 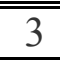 & 6.4 \\
\hline Single & - & - & $\begin{array}{l}\text { Single } \\
\text { wife/husband }\end{array}$ & 15 & 32 \\
\hline Married & 32 & 68.1 & & & \\
\hline Widowed & 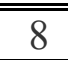 & 17.1 & & & \\
\hline divorced/separated & 7 & 14.9 & & & \\
\hline
\end{tabular}

Table.2: Levels of PTSD among elderly Syrian refugees

\begin{tabular}{||c||c||c||c||}
\hline Level & Low PTSD & Medium PTSD & High PTSD \\
\hline \hline Degree & $\mathbf{4 5 - 9 0}$ & $\mathbf{9 1 - 1 3 5}$ & $\mathbf{1 3 6 - 1 8 0}$ \\
\hline \hline $\mathbf{N}$ & 0 & 42 & 5 \\
\hline \hline $\mathbf{\%}$ & 0 & 89.4 & 10.6 \\
\hline
\end{tabular}

Table.2: Levels of PTSD among elderly Syrian refugees

\begin{tabular}{||c||c||c||c||}
\hline Level & Low PTSD & Medium PTSD & High PTSD \\
\hline \hline Degree & $\mathbf{4 5 - 9 0}$ & $\mathbf{9 1 - 1 3 5}$ & $\mathbf{1 3 6 - 1 8 0}$ \\
\hline \hline $\mathbf{N}$ & 0 & 42 & 5 \\
\hline \hline$\%$ & 0 & 89.4 & 10.6 \\
\hline
\end{tabular}




\begin{tabular}{|llc|}
\hline \hline Egyptian Journal of Social Work (EJSW) & http://ejsw.journals.ekb.eg \\
Print ISSN: $2356-9204$ & Online ISSN: 2356-9212 & Vol 8, Issue 1, June 2019 \\
\hline \hline
\end{tabular}

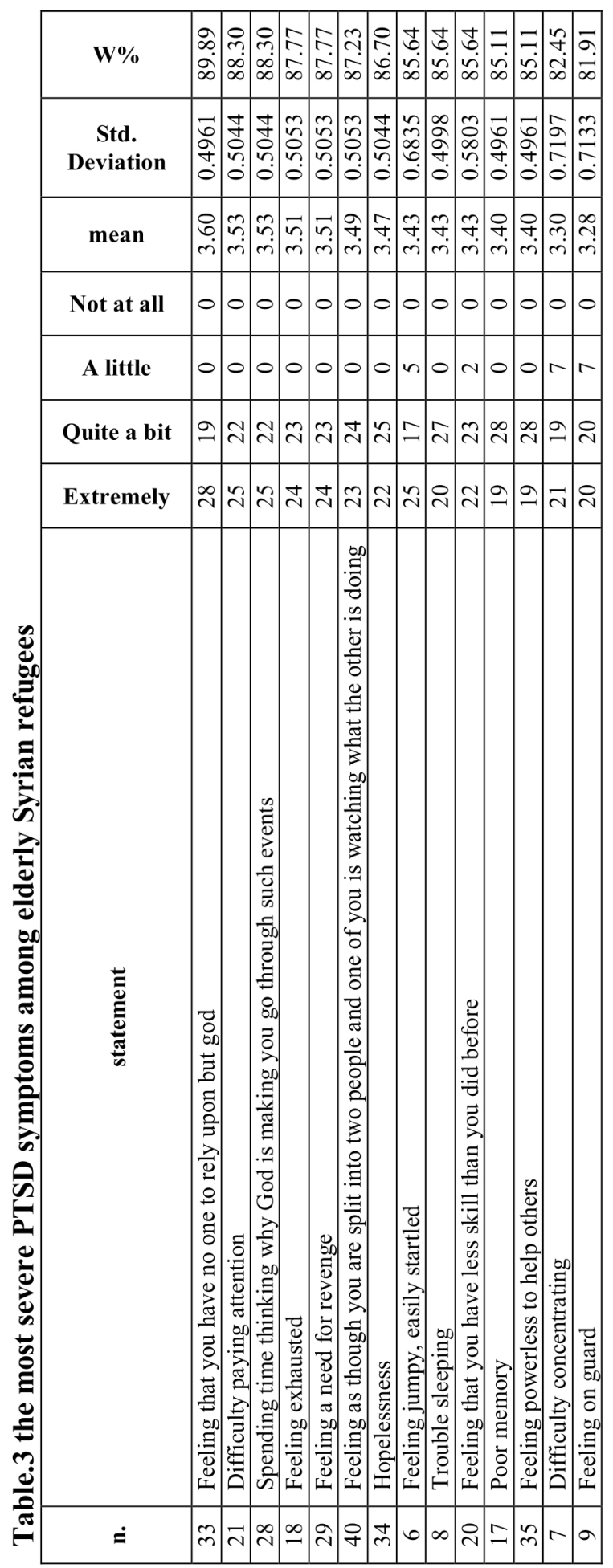




\begin{tabular}{||lcc||}
\hline \hline Egyptian Journal of Social Work (EJSW) & http://ejsw.journals.ekb.eg \\
Print ISSN: $2356-9204$ & Online ISSN: $2356-9212$ & Vol 8, Issue 1, June 2019 \\
\hline \hline
\end{tabular}

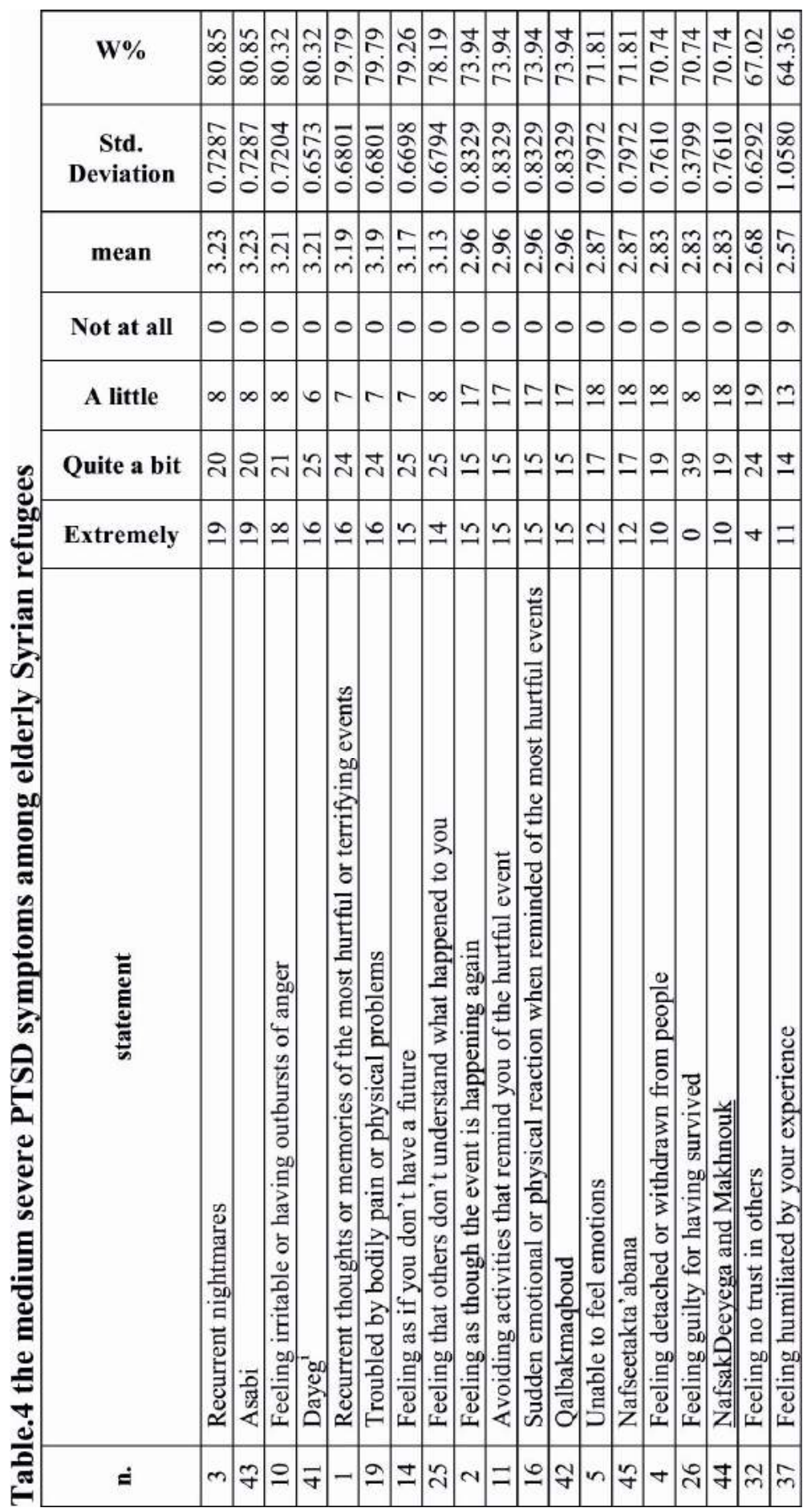




\begin{tabular}{||lcc|}
\hline \hline \multicolumn{2}{|l|}{ Egyptian Journal of Social Work (EJSW) } & http://ejsw.journals.ekb.eg \\
Print ISSN: 2356-9204 & Online ISSN: 2356-9212 & Vol 8, Issue 1, June 2019 \\
\hline \hline
\end{tabular}

\begin{tabular}{|c|c|c|c|c|c|c|c|c|c|c|c|}
\hline W\% & $=$ & $\begin{array}{l}\text { ज़े } \\
\text { bे }\end{array}$ & 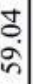 & के. & हें. & \begin{tabular}{l}
$m$ \\
\multirow{2}{q}{} \\
$\dot{q}$
\end{tabular} & & רִּ & 20 & लn & च \\
\hline $\begin{array}{c}\text { Std. } \\
\text { Deviation }\end{array}$ & $\left|\begin{array}{l}\infty \\
\tilde{\sigma} \\
\hat{\sigma} \\
\sigma\end{array}\right|$ & 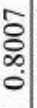 & $\begin{array}{l}\frac{0}{+} \\
\stackrel{0}{0} \\
\vdots \\
0\end{array}$ & $\begin{array}{c}\frac{\infty}{\hbar} \\
\stackrel{5}{\circ} \\
\end{array}$ & $\begin{array}{c}\frac{\infty}{\mathbb{T}} \\
\dot{0}\end{array}$ & 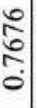 & $\begin{array}{l}\infty \\
0 \\
0\end{array}$ & 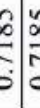 & $=\infty$ & $\frac{\infty}{\stackrel{\infty}{0}}$ & $\begin{array}{l}\text { 年 } \\
\text { ñ } \\
0\end{array}$ \\
\hline mean & 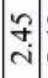 & $\stackrel{\text { ? }}{\mathrm{i}}$ & $\begin{array}{l}0 \\
i \\
i\end{array}$ & 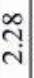 & 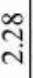 & రై & $\bar{n}$ & ; & 9 & f & $\stackrel{\text { I }}{-}$ \\
\hline Not at all & $N$ & $m$ & $m$ & in & in & $\dot{N}$ & సे & 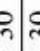 & pீ & ల్ల & 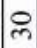 \\
\hline A little & $|\bar{N}|$ & งิ & సे & $\underset{\sim}{\infty}$ & $\underset{\sim}{\infty}$ & 2 & $\approx:$ & $E=$ & $=$ & $=$ & $\simeq$ \\
\hline Quite a bit & 으. & $=$ & 의 & 의 & 으 & $N$ & ○. & 0.6 & 0 & 6 & N \\
\hline Extremely & $a$ & ○) & in & + & + & $N$ & 0 & 0 & 0 & 0 & 0 \\
\hline 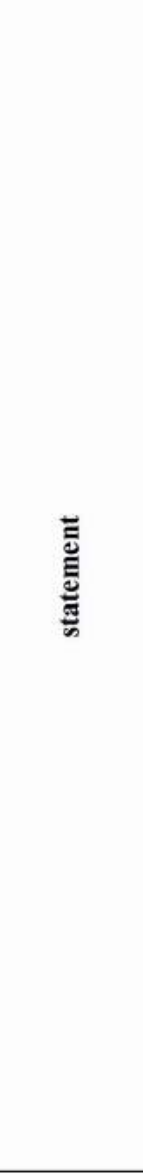 & 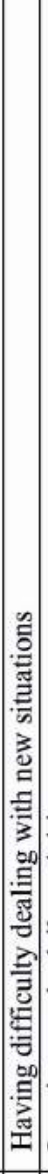 & 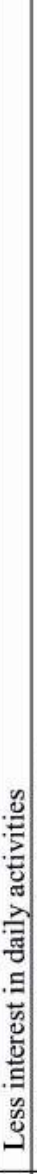 & 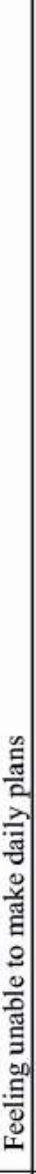 & 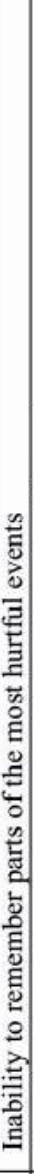 & 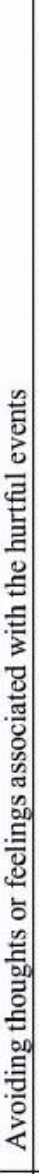 & 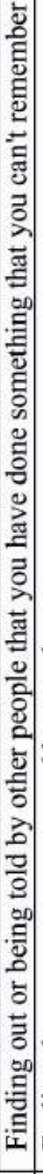 & 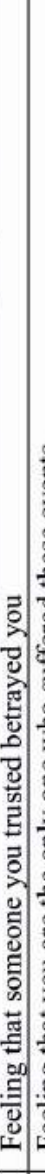 & 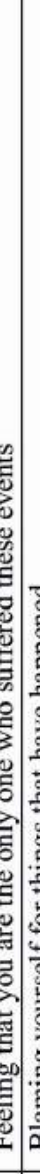 & 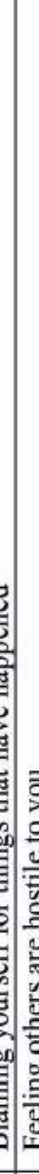 & 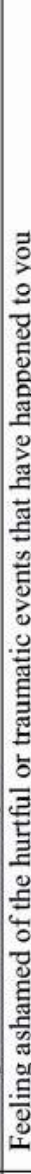 &  \\
\hline$=$ & $\approx$ & 9 & त) & $\simeq$ & - & ले| & $\bar{m}$ & \pm & जल &  & \\
\hline
\end{tabular}




\begin{tabular}{||lcc|}
\hline \multicolumn{2}{|l|}{ Egyptian Journal of Social Work (EJSW) } & http://ejsw.journals.ekb.eg \\
Print ISSN: $2356-9204$ & Online ISSN: 2356-9212 & Vol 8, Issue 1, June 2019 \\
\hline
\end{tabular}

Table.6 PTSD among elderly Syrian refugees according demographic characteristics

\begin{tabular}{|c|c|c|c|c|}
\hline variables & $\mathrm{N}$ & $\%$ & Mean & S.D \\
\hline Age & \multicolumn{4}{|c|}{$\begin{array}{l}\text { By One-way ANOVA test sig }=0.422>0.05 \\
\mathrm{f}=0.880 \text { No signification }\end{array}$} \\
\hline $60-70$ & 43 & $91 \%$ & 127.42 & 7.038 \\
\hline $71-80$ & 3 & $6 \%$ & 130.67 & 6.429 \\
\hline$>80$ & 1 & $2 \%$ & 120 & - \\
\hline total & 47 & $100 \%$ & 127.47 & 6.993 \\
\hline Gender & \multicolumn{4}{|c|}{$\begin{array}{l}\text { By Ttest sig }=0.731>0.05 \mathrm{t}=0.346 \mathrm{No} \\
\text { signification }\end{array}$} \\
\hline Male & 17 & $36 \%$ & 12127.94 & 7.798 \\
\hline Female & 30 & 64.8 & 127.2 & 6.62 \\
\hline total & 47 & $100 \%$ & 127.47 & 6.993 \\
\hline Marital status & \multicolumn{4}{|c|}{$\begin{array}{l}\text { By One-way ANOVA test sig }=0.308>0.05 \\
\mathrm{f}=1.210 \text { No signification }\end{array}$} \\
\hline 1 & 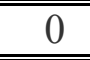 & $0 \%$ & 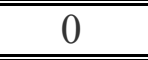 & 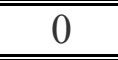 \\
\hline 2 & 32 & $68 \%$ & 128.22 & 7.161 \\
\hline 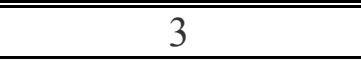 & 8 & $17 \%$ & 127.75 & 6.364 \\
\hline 4 & 7 & $15 \%$ & 123.71 & 6.576 \\
\hline Total & 47 & $100 \%$ & 127.47 & 6.993 \\
\hline $\begin{array}{l}\text { Period of stay in } \\
\text { refuge country }\end{array}$ & \multicolumn{4}{|c|}{$\begin{array}{l}\text { By One-way ANOVA test sig }=0.707>0.05 \\
\mathrm{f}=0.349 \text { No signification }\end{array}$} \\
\hline $0-12$ & 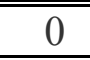 & $0 \%$ & & \\
\hline $13-24$ & 8 & $17 \%$ & 128.25 & 9.036 \\
\hline $25-36$ & 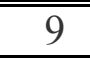 & $19 \%$ & 128.89 & 4.807 \\
\hline$>36$ & 30 & $64 \%$ & 126.83 & 7.091 \\
\hline total & 47 & $100 \%$ & 127.47 & 6.993 \\
\hline Family life cycle & \multicolumn{4}{|c|}{$\begin{array}{l}\text { By One-way ANOVA test sig }=0.459>0.05 \\
\mathrm{f}=0.879 \text { No signification }\end{array}$} \\
\hline Parental stage & 13 & $28 \%$ & 127.23 & 7.563 \\
\hline Post- Parental stage & 16 & $34 \%$ & 128.38 & 5.92 \\
\hline couple & 3 & $6 \%$ & 132.33 & 11.015 \\
\hline Single wife/husband & 15 & $32 \%$ & 125.73 & 6.892 \\
\hline total & 47 & $100 \%$ & 127.47 & 6.993 \\
\hline
\end{tabular}


